\title{
LA ACTUACIÓN DEL INSTITUTO NACIONAL DE COLONIZACIÓN EN EL MUNICIPIO DE HELLÍN (ALBACETE)
}

\author{
Gregorio Canales Martínez \\ David Jerez Cordero
}

\section{RESUMEN}

A mediados de la década de los cincuenta de la centuria actual, el Estado declara el Canal de Riegos de Hellín, en la provincia de Albacete, de alto interés nacional para la colonización agrícola. Para la puesta en riego se contó con una concesión de caudales del río Mundo de 1.000 l/s, así como del alumbramiento de aguas hipogeas. Con ello se pretendía paliar la crisis económica por la que atravesaba el municipio hellinero, derivada de la ruina de la tradicional industria textil ligada al aprovechamiento del esparto. A partir de entonces se inicia una importante transformación del espacio mediante la distribución de 1.755 ha a unos doscientos colonos, que se agrupan en tres poblados rurales de nueva construcción: Nava de Campana, Mingogil y Cañada de Agra. El desarrollo y los pormenores de esta labor colonizadora son abordados en esta monografía.

\begin{abstract}
During the mid-50's in the present century, the State declares the Irrigation Canal of Hellín, in the province of Albacete, of high national interest for agricultural colonization. A grant of flows of 1.000 1/s from the river Mundo, as well as from the extraction of hypogeum waters, was awarded for the starting of irrigation. This way, they intended to palliate the economic crisis that the Hellín municipality was going through, as a result of the collapse of the traditional textile industry related to the exploitation of esparto. From that moment onwards an important transformation of the space starts through the distribution of 1.755 hectares among some two hundred farmers, who group themselves in three new-built rural towns, namely: Nava de Campana, Mingogil and Cañada de Agra. The development and details of this colonizing task are dealt with in this monographic study.
\end{abstract}

El Instituto Nacional de Colonización inicia sus actividades, como organismo 
dependiente del Ministerio de Agricultura, en octubre de $1939^{1}$. Su creación estuvo motivada por la necesidad de efectuar una reforma tanto social como económica de la tierra, después de la guerra civil. El objetivo principal del mismo no era otro que efectuar la transformación del espacio productivo mediante su reorganización y el incremento de la superficie regada.

Fruto de la amplia acción colonizadora iniciada por el Estado a través del mencionado Instituto, es la labor realizada en el término municipal de Hellín, en la provincia de Albacete, que se conoce con el nombre de Canal de Riegos de Hellín.

El Plan General y de Obras para la colonización de las tierras afectadas por la infraestructura de riegos del Canal de Hellín, fue redactado en octubre de 1957. Un año antes el Ministerio de Agricultura, con fecha de 6 de julio de 1956, decretaba dicha zona de alto interés nacional para la colonización agrícola.

Para la puesta en riego, la Confederación Hidrográfica del Segura contaba con una concesión de aguas públicas hecha al municipio de Hellín, por el M.O.P.U., el 20 de enero de 1936, con una aportación de 1.000 litros por segundo, de los cuales 900 l/s eran destinados a utilidad agrícola y los 100 l/s restantes para el abastecimiento de la población. La pequeña asignación de caudales a Hellín, va unida a la construcción de los pantanos de Camarillas y Cenajo en la cuenca del Segura, en compensación a dicho municipio por la expropiación de los terrenos necesarios para su realización y que quedarían inundados por las aguas. Estos recursos hídricos serían incrementados con los aportes de aguas subterráneas que, para tal fin, alumbró el I.N.C. al norte de la zona regable, en el paraje conocido con el nombre de «El Boquerón», pozos que aportaron un volumen próximo a los 350 1/s. Con todos estos recursos hídricos se emprende a finales de los años cincuenta, el proceso de transformación de secano a regadío de las tierras dominadas por el Canal de Riegos de Hellín. Se trata en general de un proyecto que tiene como objetivo la ampliación del regadío tradicional de Hellín, al prolongar en $28 \mathrm{~km}$ el canal de riego ya existente, mejorando toda la infraestructura del mismo. De esta manera se consiguió que la superficie regada pasara de 1.183 ha a 2.938 ha $^{2}$, incremento debido a la colonización, que además llevó consigo la repoblación forestal de cerca de ocho mil hectáreas.

El área colonizada se extiende inmediatamente al sur de la población de Hellín y queda limitada al Norte por el Canal Principal; al Este por la carretera N-301 y el arroyo de Tobarra; al Sur por el río Mundo y la sierra de Cabeza Llana; y al Oeste por la rambla de Moreno o de Pepino. Forma un espacio continuo cuya altitud queda comprendida entre los 400-500 metros, siendo el Cabezo Gordo la cima culminante, por encima de los seiscientos metros.

La zona geológicamente está constituida por materiales terciarios, en los que afloran, de forma discordante, restos más antiguos del Mesozoico. Todo este espacio está formado por vaguadas, entre las que sobresalen cerros de calizas triásicas y jurásicas del Secundario. Las vaguadas, desde el punto de vista edáfico, constituyen suelos de extraordinada calidad, al estar recubierto el estrato Mioplioceno por un importante manto aluvial del Cuaternario. La profundidad de esos depósitos decrece progresivamente hacia las laderas

1 Es abundante la bibliografía existente sobre la labor realizada por el I.N.C., entre ellas destacan las obras de: ORTEGA CANTERO, N.: Política agraria y dominación del espacio. Orígenes, caracterización y resultados de la política de colonización planteada en la España posterior a la guerra civil, Madrid, editorial Ayuso, colección Ciudad y Sociedad, 1979, 258 pp.; y MONCLUS, F. J.- OYON, J. L.: «Políticas y técnicas en la ordenación del espacio rural», Historia y evolución de la colonización agraria en España, vol. I, Madrid, Secretaría General Técnica, Ministerio de Agricultura, Pesca y Alimentación... et al., D. L. 1988, 476 pp.

2 Datos facilitados por Antonio Morcillo Andújar, presidente de la Comunidad de Regantes «Juan Martínez Parras», dicha asociación integra a todos los comuneros del Canal de Riegos de Hellín. 
FiguRA 1. Mapa de situación del área colonizada por el I.N.C. (en punteado) en la zona regable del Canal de Hellín.

de los mencionados cerros, hasta desaparecer en las formaciones calizas. Los suelos son de coloración rojiza clara, con una proporción alta de arcilla, bien dotados de cal y escasos en materia orgánica; así mismo presentan un gran poder absorbente y retentivo para el agua.

El proyecto de bonificación se consideró en su día de alto interés social, dado que por un lado se pretendía con él reubicar a un importante número de familias que habían sido desposeídas de sus tierras al expropiárselas para la construcción de las citadas presas. Por otro lado, se perseguía paliar la crisis económica que padecía la comarca hellinera, derivada de la ruina de la tradicional industria textil ligada al aprovechamiento del atochal.

\section{Aspectos técnicos de la colonización: infraestructuras de riego y viaria}

Los trabajos topográficos necesarios para una correcta parcelación del terreno, distribución de caminos y riegos, se realizó por el comandante Carlos Girón Setién, por encargo firmado en Madrid el 15 de enero de 1957 entre el interesado y el entonces director general del I.N.C., Alejandro de Torrejón y Montero³ ${ }^{3}$ La infraestructura de riego creada por el

3 INSTITUTO NACIONAL DE COLONIZACIÓN (MINISTERIO DE AGRICULTURA): Comprobación topográfica. Sector I de la zona regable del Canal de Hellín (Albacete), Alicante, septiembre de 1958. Archivo del I.R.Y.D.A., Alicante. 
Instituto fue una prolongación en $28 \mathrm{~km}$ del Canal de Cintura o Principal ya existente, del cual derivan las acequias menores; el sistema se completa con la red de desagüe o drenaje, además de una tupida red caminera.

El canal principal se abastece del río Mundo a través del Azud de Liétor, aguas arriba del pantano del Talave y circunda toda el área de colonización con una longitud de 13 ' $5 \mathrm{~km}$, del cual deriva por sifones toda la red de riego secundaria. Esta última está formada por conducciones prefabricadas - a diferencia de la principal la cual está excavada en tierra - cuya finalidad es dar servicio a todas y cada una de las parcelas. Para ello esta red de riego que conduce el agua por gravedad — ante lo accidentado del terreno- se encuentra sobreelevada, alcanzando en ocasiones una altura de hasta dos metros. En su conjunto la red de acequias secundarias alcanza una longitud de 140 ' $4 \mathrm{~km}$ y es capaz de conducir hasta 180 1/s, equivalentes a 6 módulos (a razón cada módulo de 30 1/s) con una sección más amplia que la dotación de agua prevista, para poder conducir en su día nuevos caudales, en caso de incrementarse las dotaciones hídricas de este regadío.

La infraestructura de riego se completa con la de drenaje. Esta red tiene una profundidad entre los cuarenta y ochenta centímetros, a lo largo de $115 \mathrm{~km}$, para recoger así el agua de escorrentía superficial como la de avenamiento. Con ello se permite el desarrollo radicular de las especies arbóreas, previstas en la zona de colonización. La red de desagüe muere en las ramblas de Moreno y de Agramón, que constituyen los ejes de avenamiento natural del terreno hacia el río Mundo, aguas arriba del pantano de Camarillas.

Además de las infraestructuras de riego, el Instituto llevó a cabo la creación de una intensa red caminera con una longitud próxima a los $120 \mathrm{~km}$. Esta última se proyecta contigua a la anterior con el fin de facilitar su construcción y conservación, dado que para la misma se utilizaron las tierras procedentes de las excavaciones de los canales de riego y

FiguRA 2. Red de riego elevada en las inmediaciones del poblado de Mingogil para hacer posible la distribución del agua por gravedad. 
avenamiento. Los viales tienen una anchura de 6 ' $5 \mathrm{~m}$, de los cuales cinco metros se encuentran afirmados. De ellos deriva una multitud de caminos secundarios que dan acceso a los diferentes lotes agrícolas, encontrándose estos simplemente explanados y sin afirmar, con un ancho útil de 2'5 m. En la creación de las infraestructuras se tuvieron en cuenta todas las servidumbres de paso correspondientes, que son de un metro de ancho a ambos lados de la obra cuando esta va en solitario, y de dos metros cuando van en paralelo los viales de acceso con los de riego ${ }^{4}$.

\section{La estructura de propiedad de la tierra previa a la colonización}

La estructura de propiedad de la tierra objeto de transformación por el Canal de Riegos de Hellín, se caracteriza por el predominio de la gran explotación. El I.N.C. para llevar a cabo sus objetivos tuvo que proceder a la expropiación forzosa de la tierra de todos los titulares absentistas de la zona, manteniendo a los que eran cultivadores directos - tanto personalmente como con contratos de aparcería - un lote de tierra en concepto de reserva. En total son catorce las personas afectadas a las cuales, según preceptuaba la Ley de 27 de abril de 1946, se les aplicó la confiscación forzosa, haciéndose públicas sus fincas en el Boletín Oficial de la provincia de Albacete de 23 de enero de 1957.

La incautación de tierras se realizó fijando como expropiables aquellas parcelas que por sí solas, o sumadas a otras colindantes, tuvieran extensión suficiente para su puesta en riego, pudiendo ser del mismo propietario o de algunos de los afectados por la expropiación, y que constituyan como mínimo un patrimonio familiar.

A los propietarios objeto de confiscación se les concedió, previa petición de los interesados, la posibilidad de mantener en el nuevo regadío un lote de tierra de hasta 20 ha para los que tuvieran en propiedad menos de 100 ha, y a los que superaran dicha extensión se les concedía en concepto de reserva hasta una quinta parte de la superficie regable expropiada, siempre y cuando fueran cultivadores directos ${ }^{5}$.

De los catorce grandes propietarios existentes en la futura zona de puesta en riego, la mitad de ellos explotaban sus tierras directamente, mientras que cinco hacendados lo hacían mediante una relación contractual de aparcería, y tan solo dos terratenientes las tenían dadas en arrendamiento; estos últimos fueron desposeídos en su totalidad. El cuadro I recoge la superficie total que estos propietarios poseían así como la incluida dentro de la zona propuesta para el riego y que administraría el I.N.C.

En su conjunto se trata de predios de gran tamaño, el menor supera las 55 ha y el mayor llega hasta las 1.290 ha. La extensión total de estos latifundistas era de 7.598 ha, de las cuales el 23'1\%, es decir 1.755 ha, fueron expropiadas por el Estado para su posterior reparto a los colonos. Superficie esta que, en una ínfima parte, contaba con aprovechamientos de regadío, bien por extracciones subálveas o por derivación de las aguas de rambla, con una extensión total que apenas superaba las 10 ha. El resto de la tierra se consideraba apta para el riego, de ellas el $62 \%$ estaban dedicadas al aprovechamiento extensivo del cereal y con porciones reducidas de olivar; mientras que el 37,4\% estaba cubierto por el espartizal y mantenía un aprovechamiento ganadero.

4 INSTITUTO NACIONAL DE COLONIZACIÓN (MINISTERIO DE AGRICULTURA): Zona regable del Canal de Hellín (Albacete). Proyecto de redes de acequias, desagües y caminos rurales, Alicante, febrero de 1958. Archivo del I.R.Y.D.A., Alicante.

5 INSTITUTO NACIONAL DE COLONIZACIÓN (MINISTERIO DE AGRICULTURA): Informe y propuesta sobre expropiación forzosa por causa de interés social de varias fincas del sector I de la zona regable de Hellín (Albacete), Alicante, diciembre de 1956. Archivo del I.R.Y.D.A., Alicante. 


\section{CUADRo I}

RELACIÓN DE PROPIETARIOS CON MÁS DE 20 HA AFECTADOS POR LA EXPROPIACIÓN EN LA ZONA REGABLE DEL CANAL DE HELLÍN. AÑO 1956.

\begin{tabular}{|llrrr|}
\hline Propietarios & $\begin{array}{l}\text { Sistemas de } \\
\text { explotación }\end{array}$ & $\begin{array}{c}\text { Superficie } \\
\text { Total (Ha) }\end{array}$ & $\begin{array}{c}\text { Has Expro- } \\
\text { piadas }\end{array}$ & $\%$ \\
\hline Ant ${ }^{\text {O Preciado Monseríe }}$ & Cultivador directo & 505,8789 & 44,7736 & 8,9 \\
Hnos. Tomás Precioso & Aparcería & $1.290,1680$ & 170,9136 & 13,2 \\
J. Fernández Nieto & Cultivador directo & $1.015,7239$ & 150,9568 & 14,9 \\
B. Gallego Falcón & Cultivador directo & 169,9730 & 72,3125 & 42,5 \\
Hnos. Gallego Falcón & Cultivador directo & $1.192,9185$ & 120,4025 & 10,1 \\
P. Izquierdo Vielsa & Aparcería & 105,2105 & 73,3760 & 69,7 \\
J. Villena Espallardo & Cultivador directo & 55,7929 & 51,7109 & 92,7 \\
D. Fernández Fernández & Cultivador directo & 206,7227 & 48,5463 & 23,5 \\
Hnos. Serena Guirao & Arrendamiento & 514,6596 & 277,2087 & 53,9 \\
Hnas. Marín Precioso & Cultivador directo & 94,7423 & 65,1728 & 68,8 \\
Hnos. Guirado Precioso & Arrendamiento & 716,8905 & 159,6205 & 22,3 \\
E. Millán Villote & Aparcería & 809,2450 & 84,2304 & 10,4 \\
Ant ${ }^{\circ}$ Millán Pallarés & Aparcería & 359,6547 & 357,7427 & 99,5 \\
Hnos Millán Pallarés & Aparcería & 560,4416 & 78,0007 & 13,9 \\
\hline Total & - & $7.598,0221$ & $1.754,9680$ & 23,1 \\
\hline
\end{tabular}

FuENTE: Vid. nota núm. 5. Elaboración propia.

La superficie total requisada fue suficiente para atender las necesidades derivadas del traslado de las 97 familias de cultivadores, afectados por la construcción de las represas del Cenajo y Camarillas; y para asentar a los arrendatarios y aparceros de las tierras confiscadas. A todos ellos se les adjudicaría una parcela de 5 ha y una vivienda en los poblados que se tenía previsto construir.

\section{Los nuevos propietarios agrícolas surgidos de la colonización}

La superficie agrícola que en la zona del Canal de Hellín administró el I.N.C., se lotificó para su posterior reparto a los colonos, los primeros en establecerse lo hicieron iniciado el año 1966 y los últimos llegaron en 1972, en total se asentaron unas doscientas familias.

En un primer momento, las relaciones establecidas entre los colonos y el Estado a través del Instituto fue de tutela, implantada mediante convenios de aparcería y cuyo período de duración se determinó en cinco años, tiempo suficiente para que el colono reintegrara la cuantía de todas las mejoras realizadas en las parcelas o el valor de los bienes entregados para que esta estuviera definitivamente puesta en cultivo ${ }^{6}$. Terminado el período de tutelaje, se inicia el de acceso a la titularidad de la tierra, por el cual el colono pasa

6 GÓMEZ AYAU, E.: Tutela, posesión y propiedad, Madrid, I.N.C., serie estudios n. ${ }^{\circ}$ 15, vol. III, 1945, $31 \mathrm{pp}$. 
FiguRa 3. Cultivo asociado de herbáceos y frutales en la zona regada de Nava de Campana.

de la modalidad de posesión a la plena propiedad, a partir de la amortización de un préstamo al 3\% de interés durante un plazo inferior a treinta años.

En el transcurso de esta fase, los colonos eran adiestrados sobre las prácticas de cultivo en regadío por mayorales procedentes de la Escuela de Capataces Agrícolas, dependiente de los Centros Técnicos de Colonización que el Instituto mantenía. Cada mayoral ejercía su control sobre un determinado número de lotes agrícolas — alrededor de treinta - encargándose de la formación profesional y técnica de los colonos asignados.

De entre estos mayorales, existía un responsable en cada uno de los tres poblados de colonización creados por el I.N.C., tarea ejercida por los hermanos Antonio y Juan García Martínez en Cañada de Agra y Nava de Campana respectivamente, y por Eliseo Terol Pons en Mingogil. Los dos primeros procedían de la huerta murciana y el tercero de la valenciana, contaban por consiguiente de un conocimiento amplio de las faenas y labores propias del regadío. A su vez, éstos ejercían su autoridad bajo la supervisión del perito agrícola José Montes García, siendo el responsable máximo el ingeniero agrónomo Francisco Mira Cánovas que actuaba de jefe de explotación de toda el área colonizada ${ }^{7}$.

Para acceder a la categoría de colono, además de las prioridades ya señaladas de ser familia desalojada por la construcción de los embalses o en su defecto ser arrendatario o aparcero de la zona, se determinó al margen de las anteriores, como requisitos mínimos a cumplir los siguientes: acreditar que se estaba trabajando en la agricultura, al menos durante dos años consecutivos; ser mayor de 23 años, o haber cumplido el servicio militar,

7 Nuestro agradecimiento a Francisco Vicente Sarabia, administrativo del Servicio de Estructuras Agrarias de Castilla la Mancha y encargado de la liquidación de la zona colonizada del Canal de Hellín, sin cuya colaboración no hubiera sido posible la realización de esta monografía. 
y menor de 50 años; estar desprovisto de taras hereditarias o fisiológicas que imposibiliten o dificulten el desempeño del trabajo agrícola; poseer el certificado de escolaridad (estudios primarios) o en su defecto la tarjeta de promoción cultural, y por último, demostrar unas dotes de moralidad y conducta aceptable.

La oferta de tierras atrajo, ante los requisitos tan simples establecidos, una demanda de peticiones muy elevada, procedentes en un gran número de la provincia de Albacete, así como de las áreas vecinas de Murcia y Alicante, próximas a la zona de colonización, e incluso también de Andalucía, motivadas todas ellas por la búsqueda de mejores tierras de cultivo y con el deseo de elevar su nivel de vida.

Hechos estos que pueden ser constatados por la afluencia de inmigrantes procedentes de San Isidro de Albatera, Alcantarilla de Jover y Camarillas. El primero es un poblado de colonización creado por el Instituto en la provincia de Alicante, en terrenos de saladares, cuya bonificación se paralizó al alumbrarse aguas salinas que resultaron inservibles para el lavado de la tierra; esta situación provocó el transvase de colonos de una zona a otra ${ }^{8}$. En el caso de los dos últimos se trata de aldeas próximas al municipio de Hellín, en las cuales la emigración de sus habitantes está relacionada directamente con la desaparición de los poblados bajo las aguas, al construirse los vasos de El Cenajo y Camarillas, este último situado en su totalidad en el término hellinero.

\section{Lotificación de las tierras colonizadas y características de la puesta en cultivo}

Cuando el I.N.C. se hizo cargo de las tierras, los rendimientos agrarios que en ellas se lograban eran escasos. El esparto era uno de los aprovechamientos que cubría mayor extensión, si bien su rentabilidad iba a la baja, debido a la competencia a mediados de los años sesenta de las fibras sintéticas, unido al alto coste necesario para su recolección. Las superficies que reunían mejores condiciones estaban dedicadas al cultivo del cereal y arbolado de secano.

La puesta en riego supuso una transformación profunda del espacio, con la aparición de usos más intensivos entre los que cabe citar las hortalizas y los frutales de ciclo corto.

El lote de tierra entregado a los colonos fue en un primer momento de 5 ha, siendo el tamaño entregado a los obreros agrícolas de 0,5 ha, superficie que se consideraba necesaria para constituir un huerto de tipo familiar.

La puesta en cultivo del terreno no resultó una tarea fácil, derivada de las dificultades propias de la transformación de secano a regadío, a la que hay que añadir todos los problemas emanados de la adaptación a los nuevos terrenos y cultivos. Aspectos estos que hemos podido constatar por las conversaciones mantenidas con los colonos, cuyos testimonios ponen de manifiesto que los inicios de la colonización fueron años muy duros, en los que «se trabajaba la tierra de sol a sol», lográndose rendimientos satisfactorios una vez transcurridos varios años de la puesta en cultivo. No hay que olvidar que se trataba de yermos improductivos o terrenos que en el mejor de los casos estaban dedicados al espartizal.

Algunos colonos ante los escasos rendimientos agrícolas y la presión que sobre ellos ejercía el I.N.C., en los primeros años, se vieron obligados a abandonar sus lotes de tierra al no disponer del capital suficiente para realizar todas las mejoras que requería la explotación, pues practicaban una agricultura de autoabastecimiento, en la que apenas quedaban

8 CANALES MARTÍNEZ, G.: «Los saladares de Albatera: un intento de colonización actual», Estudios Geográficos, Madrid, noviembre de 1981, pp. 453-481. 
FIGURA 4. Los frutales, principalmente el albaricoquero, han sustituido a los tradicionales aprovechamientos extensivos del secano, que subsisten en zonas accidentadas (atochar).

FiguRA 5. En el espacio colonizado se mantienen en algunas parcelas los antiguos cultivos de secano, como en este caso el olivar. 
excedentes para su posterior comercialización. Dicha situación de descapitalización, se vio agravada por la circunstancia de que al no ser los titulares de los predios que cultivaban y carecer de otros bienes inmuebles, les imposibilitaba el acceso a préstamos bancarios.

El lote de tierra entregado tenía una cuarta parte de su superficie plantada de árboles frutales (melocotoneros y albaricoqueros preferentemente), las tres cuartas partes restantes se empleaban para el cultivo de hortalizas (tomates, cebollas, judías verdes entre otras) y cereales. También es de señalar la importancia de los forrajes (alfalfa) en la alternancia de cultivos en las tierras en blanco o de labor, que posibilitó el desarrollo ganadero como fuente complementaria de ingresos a la explotación agrícola.

Las prácticas agropecuarias que los colonos realizaban se encontraban supervisadas por personas especializadas que el Instituto puso a su servicio; además de los citados mayorales, se contaba con obreros especializados en el manejo de la maquinaria. Al iniciarse la década de los setenta, el parque móvil agrícola que se mantenía en cada uno de los poblados queda reflejado en el cuadro II. El total de maquinaria asciende a 19 tractores y 57 motocultores para los tres poblados de colonos, que contaban con el servicio de cincuenta personas especializadas contratadas para labores de apoyo a la colonización.

CuAdro II

PARQUE DE VEHÍCULOS Y MAQUINARIA AGRÍCOLA PROPIEDAD DEL I.N.C. A DISPOSICIÓN DE LOS COLONOS EN LOS POBLADOS DE LA ZONA REGABLE DEL CANAL DE HELLÍN. AÑO 1970.

\begin{tabular}{|lcccc|}
\hline Maquinaria & Mingogil & Nava de Campana & Cañada de Agra & Total \\
\hline Tractores & 7 & 6 & 6 & 19 \\
Motocultor & 37 & 10 & 10 & 57 \\
Remolques & 38 & 14 & 12 & 64 \\
Pulverizadores & 1 & - & 9 & 10 \\
Coches & 12 & 5 & 3 & 20 \\
Motocicletas & 45 & 32 & 38 & 115 \\
\hline
\end{tabular}

FuENTE: Datos facilitados amablemente por Francisco Vicente Sarabia.

El año 1972 representa el final de la gestión realizada por el I.N.C., a partir de entonces las áreas colonizadas pasan a depender directamente del recién creado Instituto de Reforma y Desarrollo Agrario (I.R.Y.D.A.). Este cambio marca una nueva etapa para las tierras regadas por el Canal de Hellín, en el que la nueva política agraria del Estado, más acorde con la realidad socioeconómica del momento, modifica el tamaño de los lotes asignados a los colonos y cierra el proceso de acceso a la tierra, dando por terminada la labor colonizadora.

En ese mismo año, el entonces ministro de agricultura, Tomás Ayende García Baxter, visita la zona colonizada y mantuvo una reunión con la Junta de Colonos de Cañada de Agra. En la misma, su presidente, José Oliva García, expone la necesidad de incrementar la superficie de cultivo entregada a cada uno de ellos, al considerarla insuficiente para el mantenimiento de la unidad familiar. Petición esta que no fue desestimada, y que llevó consigo la ampliación de la extensión del lote de regadío de 5 hasta, en algunos casos, 10 hectáreas. A dicha mejora pudieron acogerse los obreros agrícolas, que se convirtieron en colonos, incrementando los huertos familiares. 
Cada poblado tenía su Junta de Colonos, que era el órgano asambleario en el cual se debatían e intentaban resolver los problemas comunales y a través de ella los colonos canalizaban sus reivindicaciones a la Administración. Con posterioridad estas Juntas derivaron en cooperativas: San Isidro en Mingogil, San José en Cañada de Agra y San Francisco en Nava de Campana; si bien, una vez que dejaron de estar bajo la supervisión de los empleados públicos, resultaron poco efectivas ante la mala gestión y el individualismo propio de los agricultores.

Según el Catastro de la Riqueza Rústica de 1983, la superficie en propiedad de los colonos era de 1.905 ha. Extensión que comprendía, además del área colonizada - 1.755 ha que habían sido expropiadas para su puesta en riego - otras 150 ha, en su mayor parte de monte, que al quedar aisladas de la zona transformada, se asignaron con la ampliación del tamaño de los lotes. Para dicho año, la distribución de la superficie del sector queda desglosada de la forma que muestra el cuadro III.

CUADRO III

DISTRIBUCIÓN DE LA SUPERFICIE SEGÚN APROVECHAMIENTOS EN LA ZONA COLONIZADA DEL CANAL DE HELLÍN. AÑO 1983.

\begin{tabular}{|lr|}
\hline Aprovechamientos & Hectáreas \\
\hline Superficie improductiva & 18,7814 \\
Superficie productiva labrada & $1.769,8958$ \\
Regadío & $1.725,9987$ \\
Herbáceos & $1.297,1025$ \\
Leñosos (frutales) & 428,8962 \\
Secano & 43,8958 \\
Herbáceos & 19,1342 \\
Leñosos (viñedo) & 24,7616 \\
Superficie productiva no labrada & 116,3438 \\
Pastos & 86,4649 \\
Forestal & 18,6350 \\
Matorral & 11,2439 \\
\hline Total superficie & $1.905,0197$ \\
\hline
\end{tabular}

Fuente: DELEGACIÓN DE HACIENDA DE ALBACETE: Catastro de la Riqueza Rústica. Relación de características. Elaboración propia.

Es de destacar el predominio del regadío que cubre el $97,5 \%$ de la superficie total labrada, con aprovechamientos de frutales en un $24,8 \%$ (428,9 ha) y de cultivos anuales en el 75,2\% restante (1.297,1 ha). El secano abarca una extensión de 43,9 ha (el 2,5\% de la superficie labrada) dedicada mayoritariamente al viñedo y a los cereales.

La actual estructura de propiedad de la tierra es una muestra evidente de la fragmentación de las explotaciones tras la actuación del I.N.C., pues de los catorce propietarios existentes antes de la colonización, se ha pasado a ciento noventa y nueve (1983), con el reparto que figura en el cuadro IV. En él se evidencia el predominio de las explotaciones comprendidas entre 5 y 10 ha - que representa el lote tipo en la colonización-y al cual pertenecen el $61 \%$ de los propietarios y la mitad de la superficie del sector. Por encima de ellas y hasta las 18 ha, se encuentran el $35,6 \%$ de los propietarios con el 47,4\% de la 
superficie, se trata de lotes que tras la ampliación abarcaron terrenos colindantes de secano o monte. Por último, aparecen tan sólo el 3,5\% de los propietarios con extensiones entre 2 y 5 ha, y que reúnen el 1,4\% de la superficie; en este intervalo se integran aquellos que fueron obreros agrícolas.

\section{CuAdro IV}

CLASIFICACIÓN DE LOS PROPIETARIOS DEL ÁREA COLONIZADA POR EL I.N.C. EN LA ZONA REGABLE DEL CANAL DE HELLÍN, POR SUPERFICIE DE SUS EXPLOTACIONES. AÑO 1983

\begin{tabular}{|rrrrr|}
\hline \multicolumn{1}{|c}{ Hectáreas } & Propietarios & $\%$ & \multicolumn{1}{c}{ Superficie } & $\%$ \\
\hline $2,00-2,99$ & 1 & 0,5 & 2,3369 & 0,1 \\
$3,00-3,99$ & 1 & 0,5 & 3,7000 & 0,2 \\
$4,00-4,99$ & 5 & 2,5 & 21,6427 & 1,1 \\
$5,00-5,99$ & 6 & 3,0 & 33,7650 & 1,8 \\
$6,00-6,99$ & 17 & 8,5 & 110,9655 & 5,8 \\
$7,00-7,99$ & 31 & 15,6 & 232,1731 & 12,2 \\
$8,00-8,99$ & 38 & 19,2 & 322,7315 & 16,9 \\
$9,00-9,99$ & 29 & 14,6 & 277,0332 & 14,5 \\
$10,00-10,99$ & 21 & 10,6 & 219,9431 & 11,5 \\
$11,00-11,99$ & 13 & 6,5 & 147,7292 & 7,8 \\
$12,00-12,99$ & 8 & 4,0 & 100,2722 & 5,3 \\
$13,00-13,99$ & 13 & 6,5 & 174,5173 & 9,2 \\
$14,00-14,99$ & 3 & 1,5 & 44,0121 & 2,3 \\
$15,00-15,99$ & 4 & 2,0 & 61,2047 & 3,2 \\
$16,00-16,99$ & 5 & 2,5 & 83,1394 & 4,4 \\
$17,00-17,99$ & 4 & 2,5 & 69,8538 & 3,7 \\
\hline Total & 199 & 100,0 & $1.905,0197$ & 100,0 \\
\hline
\end{tabular}

Fuente: DELEGACIÓN DE HACIENDA DE ALBACETE: Catastro de la Riqueza Rústica. Relación de características. Elaboración propia.

\section{Los núcleos de servicio en el espacio colonizado}

El asentamiento de familias en los terrenos recién roturados, llevó consigo la necesidad de crear una serie de núcleos urbanos. Tres fueron los poblados que el I.N.C. levantó en el área recién transformada: Mingogil, Nava de Campana y Cañada de Agra. Para la localización de las tres poblaciones se tuvieron en cuenta una serie de condiciones, entre las que cabe citar: que se emplazaran en zonas donde resultara fácil el abastecimiento de aguas y el desagüe de las mismas; que se situaran en áreas de fácil acceso y cuya comunicación con el núcleo rector de Hellín y con los otros poblados, se hicieran sin dificultad; que los solares fueran en terrenos de secano y, por último, que en su construcción se tuvieran en cuenta los ejidos, sin ocupar, en previsión de una posterior ampliación ${ }^{9}$.

9 INSTITUTO NACIONAL DE COLONIZACIÓN (MINISTERIO DE AGRICULTURA): Propuesta de emplazamiento y ocupación de los solares de los nuevos pueblos de «Mingogil», «Cañada de Agra» y «Nava de Campana» del sector I de la zona regable del Canal de Hellín en la provincia de Albacete, Alicante, enero de 1958. Archivo del I.R.Y.D.A., Alicante. 
En cuanto a la superficie que ocupan, esta es de 30 ha para Mingogil mientras que el solar del núcleo de Cañada de Agra es de 24,15 ha, siendo el de Nava de Campana el más pequeño con 22,60 ha. El solar elegido para el emplazamiento de la población de Mingogil, pertenecía en su totalidad a una finca propiedad de Antonio Millán Pallarés. Igualmente perteneció a un solo titular - los hermanos Serena Guirado- los terrenos donde se emplaza el nuevo pueblo de Cañada de Agra, mientras que el de Nava de Campana ocupa parte de una finca perteneciente en proindiviso a la familia Tomás Precioso y Tomás Andújar, y en otra porción a la finca de Basilisa Falcón Velasco e hijos. Se trata en cualquier caso, de terrenos comprendidos en los expedientes de expropiación forzosa por causa de interés social, acordados por el Consejo de Ministros a finales del año 1957.

Además de los tres núcleos urbanos como áreas de servicio y abastecimiento para la zona transformada, originariamente se previó la dispersión de la población, mediante la construcción de 139 viviendas en diseminado. Viviendas que se construían aisladas en las correspondientes parcelas, a lo largo de los caminos de acceso a los tres pueblos previstos, procurando quedaran lo más agrupadas posibles con vistas al abastecimiento de energía eléctrica. Aspecto este que con posterioridad se descartó, dado que suponía un incremento de los costos, optándose finalmente por la concentración de la población sólo en los tres pequeños núcleos rurales planificados, que se distribuyen de forma equidistante dentro del espacio transformado para facilitar el acceso de los colonos a los diferentes lotes.

FiguRA 6. Área de influencia urbana en la zona colonizada, según los poblados construidos por el I.N.C.: 1) Nava de Campana, 2) Cañada de Agra, 3) Mingogil; o por núcleos urbanos próximos: 4) Hellín y 5) Isso. 
El I.N.C. se encargó de llevar a cabo el alcantarillado, abastecimiento de aguas y electrificación de los núcleos. En la localización de los pueblos agrícolas se tuvo en cuenta, además, que su emplazamiento quedara libre del peligro de inundaciones u otras causas que dificulten las condiciones de habitabilidad.

Aspecto importante a señalar en la colonización del Canal de Hellín, por cuanto hace referencia a la planificación, es la distribución del territorio colonizado a determinados núcleos de atracción y servicio, que escapan más allá de los tres poblados construidos por el Instituto. Así, en concreto, la figura 6 recoge el área de influencia de cada una de las zonas colonizadas y su correspondiente núcleo de atracción, pudiéndose observar que de las cinco áreas en las que se divide el terreno, dos lo hacen por su proximidad geográfica a los núcleos consolidados de Hellín e Isso, mientras que las otras tres gravitan en los poblados de nueva creación. Es de destacar en el caso de Isso — pedanía de Hellín- que los veintidós colonos seleccionados en su día y procedentes de dicho lugar, pese a contar con vivienda en los poblados de colonización, prefirieron seguir habitando la que tenían dada la cercanía a la zona colonizada.

El cuadro $\mathrm{V}$ muestra el total de viviendas y dependencias de distinto uso que se construyó en cada una de las aldeas. Entre ellas, destaca como centro neurálgico de la citada área Cañada de Agra que, pese a mantener el mismo número de viviendas para colonos que Mingogil, supera a los otros poblados tanto en personal no agrícola como en la oferta de servicios y dependencias puestas a disposición de sus habitantes.

Dicho núcleo se constituyó en símbolo de la colonización, por la originalidad de su trazado, al adaptarse a las condiciones topográficas de la ladera en la que se asienta; con manzanas curvilíneas, dispuestas irregularmente en medio de espacios con frondosa vegetación, mientras que los otros tienen una planimetría trazada a cordel. A ello hay que sumar que este poblado diseñado por el arquitecto José Luis Fernández del Amo, fuera premio nacional de arquitectura en 1967.

\section{CUADRO V}

EDIFICACIONES CONSTRUIDAS EN LOS POBLADOS FUNDADOS POR EL I.N.C. EN LA ZONA REGABLE DEL CANAL DE HELLÍN. AÑO 1958.

\begin{tabular}{|lccc|}
\hline Inmuebles & Mingogil & Nava de Campana & Cañada de Agra \\
\hline Viv. colonos & 80 & 80 & 38 \\
Viv. obreros & 8 & 24 & 13 \\
Viv. profesionales & 3 & 7 & 3 \\
Viv. artesanos & 2 & 3 & 2 \\
Edif. Públicos & Iglesia & Iglesia & Iglesia \\
& Centro & Centro & Centro \\
& administrativo & administrativo & administrativo \\
& Dos escuelas & Tres escuelas & Dos escuelas \\
& Dispensario & Dispensario & Dispensario \\
& médico & médico & médico \\
& & Edificio social & \\
& & Hermandad sindical & \\
& & Hogar rural & \\
& & &
\end{tabular}

FuENTE: Vid. cita núm. 9. Elaboración propia. 
FiguRa 7. Plaza porticada en Cañada de Agra, cuya originalidad en su trazado urbano y el tipo de vivienda construida obtuvo el Premio Nacional de Arquitectura en 1967.

Resulta interesante el análisis de los topónimos que dan origen al nombre de cada uno de los pueblos. De esta manera, Mingogil proviene del nombre del capataz encargado de regentar las tierras de la familia Millán, donde posteriormente se ubicó el citado poblado. Este asalariado era Domingo Gil, más conocido por el sobrenombre de «Mingo-Gil», apodo que por extensión se identificó con la nueva población.

En el caso de Nava de Campana, es de señalar que el topónimo «Nava» es muy frecuente en la zona de Hellín, para definir terrenos llanos cultivados entre cerros. Aparece así el nombre de Nava para denominar algunas fincas agrícolas en el espacio colonizado, como: Nava de Don Justo, Nava de los Bautistas y Nava de Sansón, entre otras. La denominación de Nava de Campana tiene su origen en el terrateniente hellinero José Tomás Precioso - más conocido como José Campaña - que dio nombre a su finca como Nava de Campaña y que posteriormente, por un error tipográfico pasó a conocerse con ese nombre el actual poblado de colonos.

Entre los cerros de Cuchillos y Balsillas, se ubica el poblado de Cañada de Agra, cuyo topónimo está determinado por el nombre de la aldea de Agra ya existente en sus inmediaciones y por el fenómeno orográfico de la cañada donde se asienta.

El trazado urbano de Mingogil, que reúne ochenta viviendas para colonos y seis destinadas a obreros agrícolas, se emplazó en un terreno con suaves pendientes formado por una vaguada, desarrollándose el núcleo a ambos lados de la misma, que se constituye en la arteria principal de la citada población. En su centro y cerrando una espaciosa plaza rectangular, se alinean todos los edificios públicos.

Debido a las características de la vivienda, que aglutina todas las dependencias propias de la explotación agrícola, el trazado viario se proyectó de manera que el acceso a dichos usos (corrales, establos y demás) se produce por viales distintos de los que dan entrada a la 
FiguRa 8. Plano urbano del poblado agrícola de Mingogil (1992). Las manzanas en blanco corresponden a la trama trazada inicialmente por el I.N.C. en 1959: 1) iglesia; 2) viviendas de artesanos; 3) dispensario médico; 4) oficina administrativa; 5) viviendas de maestros; 6) escuelas. En punteado ampliación posterior.

parte habitada. Las fachadas de las viviendas dan a calles con poco tráfico y con abundantes zonas verdes (en las espaciosas aceras se plantó una fila de árboles). Se buscó así el trazado más racional y sobre todo económico en la ordenación planimétrica de este pueblo, al disminuir notablemente las calles dedicadas al tráfico rodado (vid. figura 8).

\section{Características y tipologías de las viviendas}

Como quedó dicho anteriormente, en la colonización del Canal de Hellín y en lo referente al asentamiento de colonos, se optó por la agrupación de todos ellos en tres núcleos de nueva construcción, descartándose la idea inicial de un hábitat disperso.

Resulta imprescindible analizar la distribución de las viviendas dado que el hábitat es un fiel reflejo del tipo de explotación agrícola que se va a imponer en el nuevo espacio regable. Para su estudio se ha seleccionado el modelo de casa que conforma el núcleo de Mingogil.

Dos son los tipos de viviendas que se adoptaron para los colonos. El primero consta de dos alturas, la planta baja con porche alberga las dependencias de salón comedor, cocina, 
Figura 9. Vivienda para colonos en Mingogil: A) alzado principal, B) alzado posterior y C) alzado lateral (dibujo de F. Sánchez Soria).

despensa, un dormitorio y aseo, distribuyéndose en la planta superior dos dormitorios. El segundo modelo incorpora una habitación más en el piso superior, resultando así una superficie útil para toda la vivienda de $99 \mathrm{~m}^{2}$, siendo la construida de $127 \mathrm{~m}^{2}$, frente a los 82 y $109 \mathrm{~m}^{2}$ respectivamente de las primeras. Con esta distinción de modelos, se consigue romper la monotonía y dar un mayor dinamismo al aspecto externo del poblado. 
Figura 10. Plano de una vivienda de colonos en Mingogil. La parte habitada está formada por: 1) porche, 2) aseo, 3) dormitorios, 4) salón-comedor, 5) cocina y 6) despensa. Las dependencias agrícolas albergan: A) porche para carros, B) cuadra, C) almacén de aperos, D) porche con cocina, E) aprisco, F) gallinero, G) cochiquera, H) pajar e I) almacén de forrajes.

Además de las anteriores, se construyó un modelo de vivienda más sencillo para los obreros agrícolas, todas ellas reunidas en una sola calle y enfiladas. Se trata al igual que las otras, de un edificio de dos plantas, formada la primera por el porche, salón comedor, cocina, despensa y dormitorio, y la segunda constituida por dos dormitorios y el cuarto de aseo; con una superficie útil y construida de 69 y $94 \mathrm{~m}^{2}$ respectivamente ${ }^{10}$.

10 INSTITUTO NACIONAL DE COLONIZACIÓN (MINISTERIO DE AGRICULTURA): Proyecto del nuevo pueblo de «Mingogil». Zona regable de Hellín (Albacete), arquitecto Jesús Ayuso Tejerizo, Madrid, abril de 1959. Archivo del I.R.Y.D.A., Alicante. 
Las viviendas para colonos se completan con todas las dependencias agrícolas necesarias para la explotación de la tierra, que se distribuyen alrededor de un gran patio. La vivienda analizada (figura 10) ocupa una superficie de $600 \mathrm{~m}^{2}$, solar que incluye la parte habitada, así como las instalaciones de uso agrícola; estas se ubican en un espacio susceptible de ampliarse en virtud a las necesidades familiares o agropecuarias.

Las dependencias agrícolas constituyen un edificio con planta en forma de L. Una de las alas alberga en planta baja el cobertizo, y en dos alturas la cuadra y el almacén de aperos en la baja, y el pajar con el almacén de forrajes en la alta. La otra ala es en su totalidad de una sola altura y reúne un pequeño porche con cocina, el aprisco, la cochiquera y el gallinero.

La totalidad de las edificaciones han sido tratadas desde el punto de vista constructivo, con gran simplicidad, buscando un sencillo y fácil efecto estético con el juego de volúmenes y colores. Esto se ha conseguido a través de la combinación de distintas alturas, de parámetros retranqueados (porches) y voladizos; así como por las diferencias de los materiales empleados en su construcción, que alternan las superficies de ladrillo caravista con las encaladas.

Desde el inicio de la colonización la construcción de viviendas en los poblados se fue realizando de forma paulatina conforme a las previsiones de llegada de colonos. Con el giro dado a la política de colonización en 1972, concluyó la incorporación de nuevos adjudicatarios a los lotes de tierra, al quedar estos ampliados hasta las $10 \mathrm{ha}$; de manera que muchas de las viviendas ya construidas y pendientes de asignación quedaron vacantes, procediéndose a un nuevo reparto entre las familias ya asentadas. Resultaron beneficiadas con otra vivienda las que acreditaron su condición de ser numerosas (en total diez familias), así mismo se dio la posibilidad de adquirirlas a todas aquellas personas vinculadas al extinto I.N.C. en los distintos servicios de apoyo a la colonización (mecánicos, tractoristas, mayorales y guardas), asignándoseles un total de veinte casas en los poblados construi$\operatorname{dos}^{11}$.

\section{Final de la colonización}

Al iniciarse la década de los ochenta de la centuria actual, el Estado abre el proceso de liquidación del área colonizada. Las primeras tierras transferidas lo fueron al Ayuntamiento de Hellín, mediante la cesión que se hizo de los terrenos de repoblación forestal y aquellos en los que se habían levantado los tres poblados agrícolas.

Con posterioridad fueron los lotes agrícolas — dado que las previsiones acordadas en su día no se cumplieron - para los que se estipuló en 1982 la amortización por los colonos de la parcela de cultivo en diecisiete anualidades, al 4\% de interés; siendo el intervalo fijado para la vivienda de veintisiete años y carente de interés. La valoración de la tierra y vivienda se hizo de una forma casi simbólica, cifrándose éstas por término medio en un millón de pesetas, siendo de setecientas mil para la parcela y de trescientas mil para la vivienda.

La falta de liquidez de muchos colonos ha motivado que no se cumplan los plazos preestablecidos, pese a la ínfima tasación fijada en su día. Así, en julio de 1992, diez años después de haberse inaugurado el acceso a la consolidación de dominios, la situación no

11 Con gratitud a José Azorín Marchante, jefe de taller del Servicio de Estructuras Agrarias de Castilla La Mancha, encargado en su día de las reparaciones y mantenimiento de la maquinaria agrícola que el I.N.C. mantenía en la zona regable de Hellín, por la valiosa aportación que nos suministró. 
resulta del todo satisfactoria, pues menos de veinte colonos llevan actualizado el saldo de su deuda. Son diez las personas que hasta la fecha no han desembolsado todavía ninguna anualidad, sin que se hayan adoptado aún contra ellos medidas coercitivas. Los restantes colonos, según hemos podido comprobar por el listado de pagos, se encuentran amortizando cantidades atrasadas, que en algún caso llega hasta los ocho años.

El I.R.Y.D.A. todavía mantiene en propiedad las instalaciones que en su día se construyeron para elevar las aguas subálveas y la pequeña presa de almacenaje, sitas en el paraje El Boquerón, con las que se pretendía incrementar las dotaciones hídricas para los riegos del Canal de Hellín. Actualmente se mantienen negociaciones para adjudicar dichas obras, estando interesados el Ayuntamiento de Hellín, la Comunidad de Regantes de Isso y la Comunidad de Regantes Juan Martínez Parras. El primero pretende con ello aumentar el volumen de agua para abastecimiento urbano, mientras que los otros dos la utilizarían con fines eminentemente agrícolas. La Comunidad de Regantes Juan Martínez Parras ${ }^{12}$, que aglutina a todos los agricultores que riegan con las aguas del Canal de Hellín, se opone a que dichas instalaciones, en virtud de su objetivo originario, pasen a depender y beneficiar a otros colectivos que no sea el constituido por los regantes para los cuales se creó.

\section{Situación actual}

De las conversaciones mantenidas con los antiguos colonos, se desprende que la situación económica por la que atraviesa la zona no es muy satisfactoria. Las quejas recibidas son de diversa índole, unas hacen referencia a los poblados de colonización y otras a la actividad agrícola.

En cuanto a las primeras, se constata el poco desarrollo que han experimentado estos pequeños núcleos rurales, si bien algunos de ellos han ampliado su superficie edificada con nuevas construcciones para los hijos de los colonos (como en Mingogil y Nava de Campana). En todos ellos se deja ver el descuido que impera en su aspecto externo, con zonas ajardinadas abandonadas y calzadas en mal estado, hechos estos que se reflejan en las respuestas de sus moradores, con frases tan llamativas como: «ahora se nota el descuido» o «cuando vinimos aquí el pueblo estaba precioso». No hay que olvidar que cuando estos poblados eran administrados por el Estado contaban con personal encargado de su mantenimiento (jardineros, barrenderos) y a su vez, las Juntas de Colonos primaban y sancionaban tanto la conservación exterior de la vivienda como de la vía pública.

También son destacables las deficiencias de estos núcleos en cuanto a servicios, dado el origen de su configuración, careciendo de asistencia médica permanente, así como de farmacia e incluso de atención religiosa; limitándose en todo caso a la visita que realiza algún facultativo, como sacerdote un día a la semana. En cuanto a la atención escolar, esta sí se encuentra plenamente cubierta.

La situación agrícola actual atraviesa una coyuntura marcadamente recesiva, motivada tanto por la falta de competitividad, como por la descapitalización de la agricultura, todo ello unido a los problemas derivados de las condiciones ambientales, lo cual se refleja en los bajos rendimientos agrícolas. Los agricultores se quejan de que «no se saca como al principio» e incluso algunos afirman que «a lo primero de estar aquí se vivía mejor que ahora». Todo ello, en consonancia con un incremento de los costos de producción, dado que en la última década — desde el acceso a la propiedad de la tierra en 1982 - se ha acometido una masiva plantación arbórea, de manera que los frutales han pasado de cubrir

12 Información facilitada por Juan José Gascón Moreno, jefe del servicio del I.R.Y.D.A. en Albacete. 
FiguRA 11. El área regada está formada por aprovechamientos herbáceos y leñosos, éstos últimos cubren cada vez mayor superficie, teniendo la primacía el albaricoquero.

el 30\% de la superficie del lote al 70-80\% del total. A modo de ejemplo, si tomamos como representativo del conjunto una explotación media de siete hectáreas, en la actualidad dos hectáreas se encuentran dedicadas a la producción de hortalizas — principalmente pimientos- quedando la restante superficie cubierta de frutales, con predominio del albaricoquero. Para dicha explotación se consideran unos beneficios brutos anuales de 2.100 .000 ptas, desglosados de la siguiente forma: 1.400 .000 de la cosecha de frutales y 700.000 de la de hortalizas; mientras que la cuantía total de gastos asciende a 1.300 .000 ptas., resultando unos beneficios netos de 800.000 pesetas anuales ${ }^{13}$.

Otros propietarios han orientado su explotación agraria hacia la ganadería, aunque tampoco este recurso ha resultado tener rentabilidad. Así, un ganadero de Nava de Campana nos precisaba que de las 8,15 ha que poseía, casi 7 ha estaban dedicadas a la producción de piensos y forrajes. Con ellas mantenía una cabaña ganadera compuesta por 400 cabezas de ovino, siendo preciso además llevar en arriendo para la alimentación de las mismas 36 ha. A pesar de la mecanización de dicha explotación y de la importancia de tal rebaño, su titular señalaba los bajos ingresos recibidos que no cubren los costes mínimos de producción ${ }^{14}$.

Como consecuencia de la baja rentabilidad por la que atraviesa el sector, el nivel de vida de estos agricultores se ha visto muy mermado, lo que ha incidido en un éxodo de mano de obra, sobre todo joven, hacia los núcleos urbanos de Madrid, Albacete y Alicante preferentemente, empleándose en otros sectores económicos.

13 Nuestro reconocimiento a Dolores Martínez Rubio, alcaldesa pedánea de Mingogil por las orientaciones recibidas acerca de las características actuales de los poblados de colonización.

14 Testimonio de Juan Montaya García, ganadero de Nava de Campana. 